\title{
Autoimmune Manifestations in Common Variable Immunodeficiency
}

\author{
C. Cunningham-Rundles \\ Mount Sinai School of Medicine, 1425 Madison Avenue, New York City 10029, USA, e-mail: \\ Charlotte.Cunningham-Rundles@mssm.edu
}

\begin{abstract}
Introduction-About 20\% of subjects with common variable immune deficiency (CVID) develop an autoimmune complication, most often immune thrombocytopenia or hemolytic anemia. While the pathogenesis of autoreactivity is unknown for CVID subjects in general, and to a greater extent in those with autoimmunity, there is a loss of switched memory B cells.
\end{abstract}

Discussion-About 7-8\% of CVID subjects have mutations in the transmembrane activator and calcium-modulating cyclophilin ligand interactor (TACI), a significant association with this immune defect, although the same mutations may be found in normal relatives and rarely in healthy blood donors. In addition to generalized B cell dysfunction, defective elimination of autoimmune B cells has been demonstrated.

\section{Keywords}

Common variable immune deficiency; memory B cell; pathogenesis; autoimmunity

\section{Autoimmunity in CVID}

\begin{abstract}
About $20 \%$ of patients with common variable immune deficiency (CVID) have autoimmune complications which are both poorly understood and, in many cases, difficult to manage on the clinical level [1]. The pathogenesis of autoimmunity in CVID has always been unclear; it remains one of the more remarkable facets of this immune defect that autoantibodies may be produced against internal tissues, whereas at the same time, few, if any, IgG antibodies can be detected in the serum after vaccination with common vaccines such as pneumococcal antigens, tetanus, or diphtheria toxoids.
\end{abstract}

In a group of 248 US subjects, autoimmunity was documented for 59 subjects who had a total of 65 conditions (22\%) [2]. In a multicenter prospective European study of a cohort of 224 Italian patients with CVID, 39 had autoimmunity at the time of diagnosis of CVID and 58 had autoimmunity during the follow-up period of 11 years [3]. Whereas many forms of autoimmunity have been noted, including rheumatoid arthritis, juvenile rheumatoid arthritis, pernicious anemia, thyroiditis, alopecia, primary biliary cirrhosis, vitiligo systemic lupus erythematosus, all series agree that of the autoimmune conditions, the commonest are antibodies to hematologic tissues, especially immune thrombocytopenia purpura and autoimmune hemolytic anemia (AIHA) (or both, Evans syndrome) [2,4,5]. Autoimmune neutropenia is less commonly found. The age at diagnosis of autoimmunity is quite variable and may precede or follow the diagnosis of immune deficiency (Table I) [4,6]. In all series of CVID subjects, a notable factor is that isolated autoimmunity may be the presenting ailment 
with no evidence of other complications such as infections, so characteristic of immune deficiency.

\section{Granulomatous Disease, Autoimmunity, and Memory B Cell Phenotype}

Whereas there are many questions about the pathogenesis of autoimmunity, one of the emerging hallmarks of this complication is the general depletion of switched memory B cells in those in whom this complication develops. Brouet et al. [7] were the first to recognize the potential lack of B cells bearing CD27 in CVID, and this was amplified by Agematsu and Ochs [8]. Subsequently, the lack of switched memory B cells (B cells of the CD27+, IgM-IgDphenotype) were characteristic of a large proportion of subjects with CVID, and that there relative lack of these cells could be used to divide patients into two clinically and immunologically different groups $[3,9,10]$. The lack of switched memory B cells was also found related to a lack of antibody production to pneumococcal vaccine, and interestingly, in these and other studies, also to the presence of autoimmune disease [11,12]. These data imply that the general immaturity of B cells, as highlighted by the lack of capacity for isotype switching in this segment of the CVID population, is a key element behind the retention of autoimmune clones.

Another closely related observation is that autoimmunity in CVID is likely to occur in subjects in whom granulomatous infiltrations in the lungs, nodes, or other organs have been documented. Although the actual incidence is unknown, as tissues are not biopsied unless an obvious clinical necessity exists, granuloma have been documented in about $7.5 \%$ to $10 \%$ of subjects with CVID [5,13,14]. Fasano et al. [13] showed that 7 of 30 patients (23\%) with granulomatous disease had autoimmunity: 5 had hemolytic anemia, 1 had pernicious anemia, and 1 had primary biliary cirrhosis. Mechanic et al. [14] also showed that 9 of 17 CVID patients (53\%) with granulomas had autoimmunity: 5 had ITP, 3 had AIHA, 1 had RA, and 1 had primary biliary cirrhosis. Perhaps because of the close relationship between these clinical outcomes, it might not be surprising that CVID subjects with granulomata are likely to have very few switched memory B cells [9-11].

\section{Autoimmunity and Mutations in TACI}

Mutations in the gene encoding the transmembrane activator and calcium-modulating cyclophilin ligand interactor (TACI) have been identified in 7-10\% of CVID subjects [15, 16]. TACI is expressed on mature B cells and activation leads to T cell-dependent and independent responses and isotype switch; however, TACI signaling also exerts an inhibitory effect as knockout mice have B cell hyperplasia, increased immune globulin (Ig) production, autoimmunity, splenomegaly, and B cell lymphomas. However, mutations in TACI are found both in normal volunteers $[17,18]$ and nonimmune-deficient family members of CVID patients, thus the association of TACI with immune deficiency is not currently well understood.

However, CVID subjects with mutations in TACI display more autoimmunity than subjects without this molecular finding. For example, of 199 subjects with CVID, 14 had TACI mutations, 7.0\%; all were heterozygous and 3 were compound heterozygotes [19]. Six (46\%) of the subjects with mutations had significant splenomegaly and one or more episodes of immune thrombocytopenia (ITP); four had undergone splenectomy (31\%). Other autoimmune/ inflammatory conditions included AIHA, granulomatous disease, juvenile rheumatoid arthritis, uveitis, and psoriasis. For 163 CVID subjects in the same group without mutations in TACI, 20 had a history of ITP, 17 had splenomegaly, 8 had splenectomy, and 6 had AIHA. Comparing CVID subjects with and without mutations, these differences were significant: ITP, $p=0.012$; splenomegaly, $p=0.012$; and splenectomy, $p=0.001$ [19]. Whereas autoimmunity and granulomatous disease share a similar peripheral B cell phenotype (a relative lack of switched memory B cells), the memory B cell phenotype in subjects with TACI mutations is quite 
heterogeneous, ranging from subjects with very few circulating B cells to subjects with an almost normal peripheral B cell phenotype.

\section{Pathogenesis of Autoimmunity}

Previous work has shown that a lack of B cell receptor signaling results in aborted B cell development, leading to X-linked or autosomal forms of agammaglobulinemia [20]. However, the few remaining B cells in these subjects can be analyzed by single-cell clonal analysis; the $\mathrm{Vh}$ regions of these cells are commonly autoreactive; $62 \%$ and $56 \%$ of clones of single cells of two XLA subjects compared to $31 \%$ for clones of controls had Vh regions with selfreactivity. Other self-reactive antibodies (DNA, insulin) were found for $50 \%$ and $37.8 \%$ of XLA clones of these individuals, as opposed to $8.2 \%$ of control clones. Not only does impaired signaling via the B cell receptor result in the capacity for autoimmunity; subjects with XLhyper-IgM also had increased numbers of self-reactive clones in circulating mature naive B cells and clones expressing a positive ANA. A similar but somewhat different phenotype was found for a child with bare lymphocyte syndrome, as the naïve B cell population contained increased ANA positive clones but not polyreactive clones [21]. Thus, removal of autoimmune $\mathrm{B}$ cells involves not only sufficient and normal B cell receptor signaling, but also T cell colligation events involving CD40L, CD40, and MHC. These and additional factors may also be important when considering the elimination of autoimmune clones in CVID; ineffective B cell receptor signaling or other abnormal ligand interactions may abrogate the removal of autoimmune B cells. B cell immaturity is present, and CD40L expression is known to be reduced in CVID [22]. For some systemic autoimmune diseases, excess levels of serum BAFF or April are viewed as leading to or accelerating ongoing autoimmunity. Although the reasons are unclear, we have found that the serum of subjects with or without autoimmunity have high levels of both BAFF and APRIL [23], suggesting that any autoimmune clones that are present in this immune deficiency are permitted a potential growth advantage.

\section{Treatment of Autoimmunity}

In most cases, the treatment of autoimmunity in CVID is the same as for immune competent subjects $[4,6]$ with the caveat that when immune suppression is used, lower doses and shorter periods of treatment are advisable, as opportunistic and or fatal complication infections become more likely with prolonged or excessive treatment (Table I). For ITP and AIHA, increased doses of immune globulin may be helpful. In fact, intravenous immune globulin used in standard doses may be prophylactic against these two complications, as in a study of 326 subjects, for the 35 subjects who had had either ITP or AIHA, 19 (54\%) had the first episode of thrombocytopenia or hemolytic anemia before the diagnosis of CVID, 11 others (32\%) were diagnosed concurrently. As only 5 (14\%) developed one or both of these complications after the diagnosis of CVID and institution of maintenance IVIg, most episodes occurred for subjects not yet on this therapy $(p<0.0001)$ [4]. The use of rituxan, an anti-CD20 monoclonal antibody, has more recently been used with success to treat ITP and AIHA in nonimmune-deficient subjects [24,25] and ITP in CVID [26] and will most likely prove a very useful therapy for more refractory episodes.

\section{References}

1. Knight AK, Cunningham-Rundles C. Inflammatory and autoimmune complications of common variable immune deficiency. Autoimmun Rev 2006;5:156-9. [PubMed: 16431351]

2. Cunningham-Rundles $\mathrm{C}$, Bodian C. Common variable immunodeficiency: clinical and immunological features of 248 patients. Clin Immunol 1999;92:34-48. [PubMed: 10413651]

3. Quinti I, Soresina A, Spadaro G, Martino S, Donnanno S, Agostini C, et al. Long-term follow-up and outcome of a large cohort of patients with common variable immunodeficiency. J Clin Immunol 2007;27:308-16. [PubMed: 17510807] 
4. Wang J, Cunningham-Rundles C. Treatment and outcome of autoimmune hematologic disease in common variable immunodeficiency (CVID). J Autoimmun 2005;25:57-62. [PubMed: 15994061]

5. Cunningham-Rundles C. Common variable immunodeficiency. Curr Allergy Asthma Rep 2001;1:4219. [PubMed: 11892068]

6. Michel M, Chanet V, Galicier L, Ruivard M, Levy Y, Hermine O, et al. Autoimmune thrombocytopenic purpura and common variable immunodeficiency: analysis of 21 cases and review of the literature. Medicine (Baltimore) 2004;83:254-63. [PubMed: 15232313]

7. Brouet JC, Chedeville A, Fermand JP, Royer B. Study of the B cell memory compartment in common variable immunodeficiency. Eur J Immunol 2000;30:2516-20. [PubMed: 11009084]

8. Agematsu K, Futatani T, Hokibara S, Kobayashi N, Takamoto M, Tsukada S, et al. Absence of memory B cells in patients with common variable immunodeficiency. Clin Immunol 2002;103:34-42. [PubMed: 11987983]

9. Warnatz K, Denz A, Drager R, Braun M, Groth C, Wolff-Vorbeck G, et al. Severe deficiency of switched memory B cells $(\mathrm{CD} 27(+) \operatorname{IgM}(-) \operatorname{IgD}(-))$ in subgroups of patients with common variable immunodeficiency: a new approach to classify a heterogeneous disease. Blood 2002;99:1544-51. [PubMed: 11861266]

10. Wehr C, Kivioja T, Schmitt C, Ferry B, Witte T, Eren E, et al. The EUROclass trial: defining subgroups in common variable immunodeficiency. Blood 2008;111:77-85. [PubMed: 17898316]

11. Ko J, Radigan L, Cunningham-Rundles C. Immune competence and switched memory B cells in common variable immunodeficiency. Clin Immunol 2005;116:37-41. [PubMed: 15925830]

12. Alachkar H, Taubenheim N, Haeney MR, Durandy A, Arkwright PD. Memory switched B cell percentage and not serum immunoglobulin concentration is associated with clinical complications in children and adults with specific antibody deficiency and common variable immunodeficiency. Clin Immunol 2006;120:310-8. [PubMed: 16782407]

13. Fasano MB, Sullivan KE, Sarpong SB, Wood RA, Jones SM, Johns CJ, et al. Sarcoidosis and common variable immunodeficiency. Report of 8 cases and review of the literature. Medicine (Baltimore) 1996;75:251-61. [PubMed: 8862347]

14. Mechanic LJ, Dikman S, Cunningham-Rundles C. Granulomatous disease in common variable immunodeficiency. Ann Intern Med 1997;127:613-7. [PubMed: 9341059]

15. Salzer U, Chapel H, Webster AD, Schlesier M, Draeger R, Schmitt-Graff A, et al. Mutations in TACI are associated with immunodeficient phenotypes in humans. Clinical Immunology 2005;115:S29.

16. Castigli E, Wilson SA, Garibyan L, Rachid R, Bonilla F, Schneider L, et al. TACI is mutant in common variable immunodeficiency and IgA deficiency. Nat Genet 2005;37:829-34. [PubMed: 16007086]

17. Salzer U, Chapel HM, Webster AD, Pan-Hammarstrom Q, Schmitt-Graeff A, Schlesier M, et al. Mutations in TNFRSF13B encoding TACI are associated with common variable immunodeficiency in humans. Nat Genet 2005;37:820-8. [PubMed: 16007087]

18. Pan-Hammarstrom Q, Salzer U, Du L, Bjorkander J, Cunningham-Rundles C, Nelson DL, et al. Reexamining the role of TACI coding variants in common variable immunodeficiency and selective IgA deficiency. Nat Genet 2007;39:429-30. [PubMed: 17392797]

19. Zhang L, Radigan L, Salzer U, Behrens TW, Grimbacher B, Diaz G, et al. Transmembrane activator and calcium-modulating cyclophilin ligand interactor mutations in common variable immunodeficiency: clinical and immunologic outcomes in heterozygotes. J Allergy Clin Immunol 2007;120:1178-85. [PubMed: 17983875]

20. Ng YS, Wardemann H, Chelnis J, Cunningham-Rundles C, Meffre E. Bruton's tyrosine kinase is essential for human B cell tolerance. J Exp Med 2004;200:927-34. [PubMed: 15466623]

21. Herve M, Isnardi I, Ng YS, Bussel JB, Ochs HD, Cunningham-Rundles C, et al. CD40 ligand and MHC class II expression are essential for human peripheral B cell tolerance. J Exp Med 2007;204:1583-93. [PubMed: 17562816]

22. Farrington M, Grosmaire LS, Nonoyama S, Fischer SH, Hollenbaugh D, Ledbetter JA, et al. CD40 ligand expression is defective in a subset of patients with common variable immunodeficiency. Proc Natl Acad Sci U S A 1994;91:1099-103. [PubMed: 7508119]

23. Knight AK, Radigan L, Marron T, Langs A, Zhang L, Cunningham-Rundles C. High serum levels of BAFF, APRIL, and TACI in common variable immunodeficiency. Clin Immunol 2007;124:1829. [PubMed: 17556024] 
24. Giulino LB, Bussel JB, Neufeld EJ. Treatment with rituximab in benign and malignant hematologic disorders in children. J Pediatr 2007;150:338-44. 344.e1. [PubMed: 17382107]

25. Godeau B, Provan D, Bussel J. Immune thrombocytopenic purpura in adults. Curr Opin Hematol 2007;14:535-56. [PubMed: 17934364]

26. Carbone J, Escudero A, Mayayo M, Ballesteros M, Perez-Corral A, Sanchez-Ramon S, et al. Partial response to anti-CD20 monoclonal antibody treatment of severe immune thrombocytopenic purpura in a patient with common variable immunodeficiency. Ann N Y Acad Sci 2005;1051:666-71.

[PubMed: 16127007] 


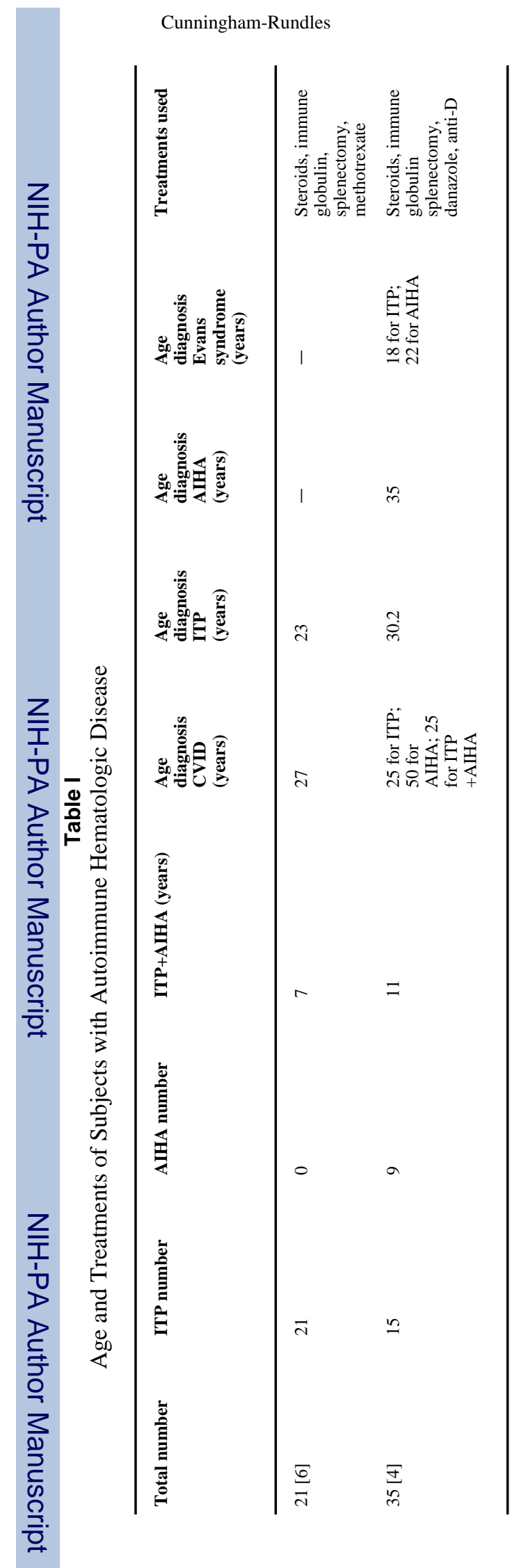

Page 6 